\title{
Lobular Neoplasia Type B
}

National Cancer Institute

\section{Source}

National Cancer Institute. Lobular Neoplasia Type B. NCI Thesaurus. Code C83171.

Lobular neoplasia of the breast characterized by the presence of neoplastic cells with nuclei of various sizes and shapes. 